\title{
Obturator Prosthesis for Edentulous Hemi-Maxillectomy patients: A Case Study
}

\author{
${ }^{1}$ Meriem OUAALLA, ${ }^{2}$ Khadija EL ASSRAOUI, ${ }^{3}$ Aicha OUBBAIH, ${ }^{4}$ Samira BELLEMKHANNATE \\ ${ }^{1}$ Resident Doctor, ${ }^{2}$ Assistant Professor, ${ }^{3}$ Specialist Doctor, ${ }^{4}$ Professor \\ Department of Removable Prosthodontics \\ Faculty of Dentistry, Hassan II University of Casablanca
}

Post code 21100, Casablanca

Morocco

\begin{abstract}
The maxillary tumors include various histological entities which are the subject of a very particular treatment. Clinical, radiological and anatomopathological criteria are used to determine the diagnosis. In spite of the evolution of reconstructive surgical techniques and the development of microsurgery, the conventional obturator prosthesis is still in use nowadays. In this context, it must restore the main functions of chewing, phonation and deglutition and give the patient a satisfactory aesthetic appearance.
\end{abstract}

Keywords: Obturator prosthesis, Maxillary substance loss, Prosthetic rehabilitation.

\section{INTRODUCTION}

The maxillofacial complex is the seat of the mimicry, the organs of olfaction, vision, hearing and gustation and the origin of the respiratory and digestive tracts. This anatomical part has a major relational importance.

Once the diagnosis has been confirmed, the primary treatment of maxillary tumors consists mostly of a carcinologic excision surgery associated or not with radiotherapy and / or chemotherapy [1-2].

This more or less extended maxillectomy involves a loss of substance of variable size, which is accompanied by serious functional, aesthetic and psychological consequences [3-4].

The rehabilitation of these defects is therefore primordial in order to minimize these effects, but also to allow the patient to regain as optimal a quality of life as possible [5].

In spite of the evolution of reconstructive surgical techniques and the development of microsurgery, the conventional obturator prosthesis is still in use, where the repairing surgery has failed or is impossible or as transitory prosthesis until surgical repair while awaiting surgical repair.

It also aims to restore the tightness at the substance loss in order to restore the main functions of chewing, deglutition, phonation and to give the patient a satisfactory aesthetic aspect that will allow an acceptable socio-professional reintegration [6].

The aim of this article is to address the need for prosthetic rehabilitation in the management of patients with maxillary substance loss. 


\section{CASE REPORT}

A 67 year old male patient was referred to the department of prosthodontics by his maxillofacial surgeon, after resection of an epidermoid carcinoma affecting the right maxilla for an aesthetic and functional prosthetic rehabilitation.

The clinical examination allows detecting a right genial tissue depression; the scar of the superior hemi-lip caused by the discharge of the maxillectomy bridle creates labial incompetence (Figure 1) .

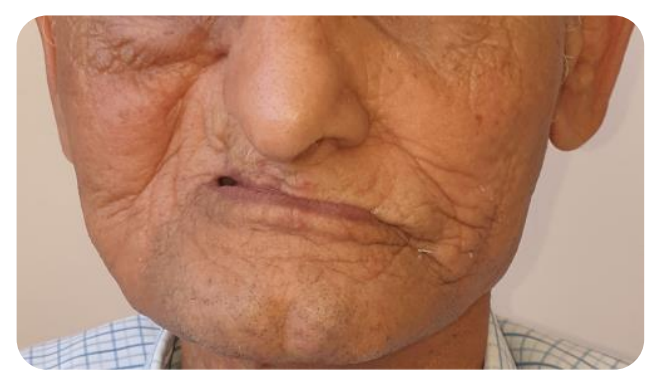

Figure 1: Extra-oral view of the maxillary defect.

The patient complained of difficulty in mastication, nasal regurgitation of fluids, nasal tone in his voice.

Intra-oral examination showed a completely edentulous maxilla and the defect was classified as BOUTAULT's class III i defect [7].

The opposite side of the arch is completely edentulous (Figure 2).
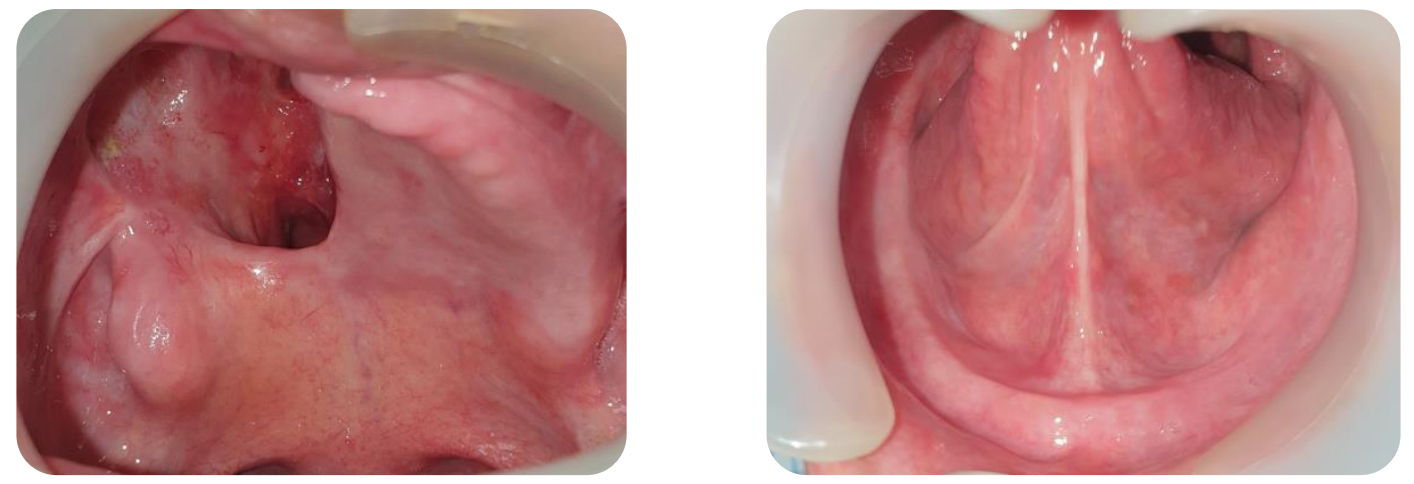

Figure 2 : Intraoral l view of the maxillectomy defect.

The steps for making the obturator prosthesis were not different from those for making a conventional complete denture, except certain some specificities described below.

On the initial impression, Vaseline-embedded gauze was inserted into the palate cavity in order to prevent excess impression material extravasation into the nasal cavity; the impression tray was chosen according to the patient arch size and the impression was performed with irreversible hydrocolloid (Figure 3). 


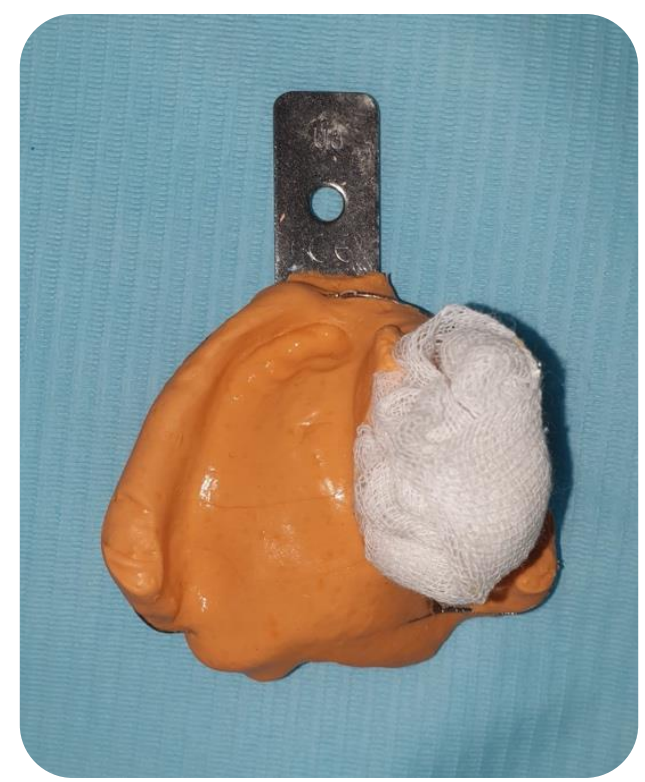

Figure 3: Primary impression.

The functional impression was made using custom impression trays (Fig. 4). The communication area must be protected with gauze embedded in Vaseline and the edges of the cavity must always be kept free of material after impression taking.

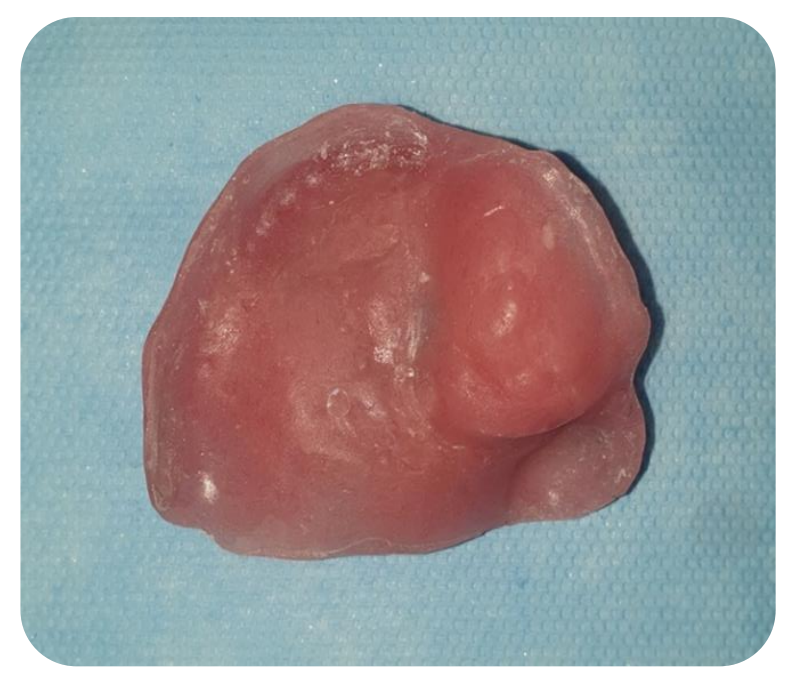

Figure 4: Individual impression tray used to make the anatmo-functional impression.

After border molding, the final impression performed with polysulfide (Permlastic Regular body; Kerr) (Figure 5).

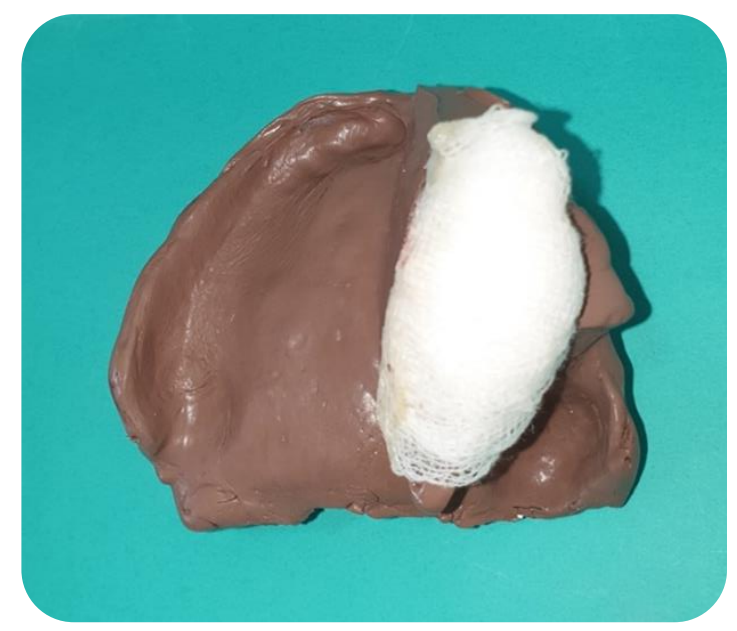

Figure 5: Global impression of the palatal surface using a polysulfide 


\section{International Journal of Advances in Scientific Research and Engineering (ijasre), Vol 6 (10), October -2020}

After the occlusion casts were realized, the steps of registering the intermaxillary relationship were started.

The occlusal rim was adjusted to support the peripheral musculature and replace missing jaw bone, alveolar bone and dental arch. The determination of the orientation and position of the occlusal plane follows the esthetic and functional criteria of the conventional complete denture.

After adjustment of the labial support and the occlusal plane, the vertical dimension of the occlusion has been determined according to the harmony of the face, and casts were transferred to an articulator.

The setting of the teeth was realized according to the rules of the balanced occlusion concept, and a wax try-in was performed (Figure 6).

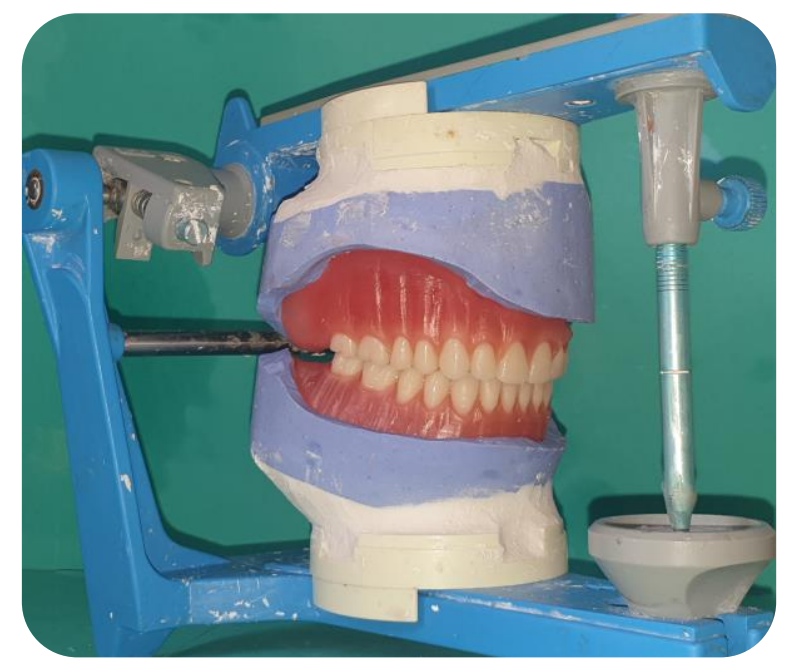

Figure 6: Waxed up Prosthesis.

After the trial, the wax obturator was treated in the conventional manner. The finishing and polishing of the obturator prosthesis was carried out.

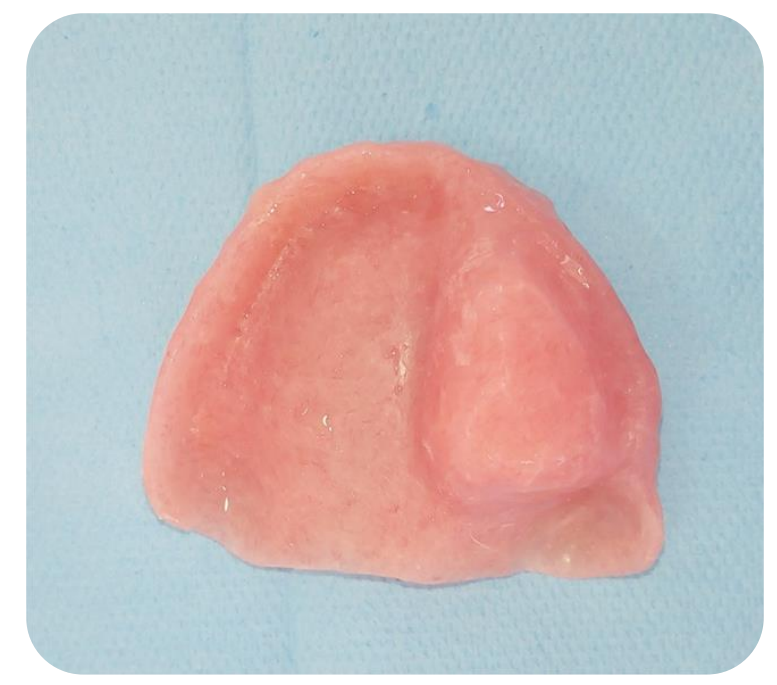

Figure 7 : The permanent obturator

The obturator prosthesis was then inserted into the patient's mouth after intraoral adjustments.

The patient was examined periodically for 12 months. He was very satisfied with his prosthesis both functionally and aesthetically (Figure 8). 

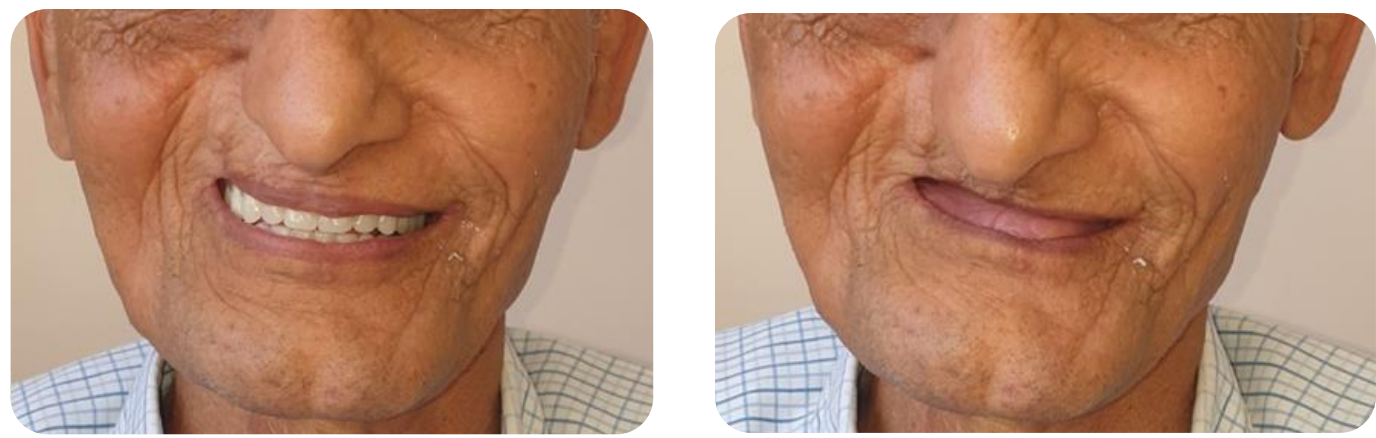

Figure 8 : Smiling profile of the patient before and after insertion of the prothesis.

\section{DISCUSSION}

The natural appearance and esthetic realization of conventional removable prostheses are in every individual situation a challenge for both the dentist and the technician [8] which is even more complicated in the case of a completely edentulous patient with a maxillectomy.

Rehabilitation of the patient presenting with a malignant tumor in the maxilla requires a multidisciplinary approach including surgical treatment, radio/chemotherapy, phonetic rehabilitation, physiotherapy, and prosthetic treatment [9].

All healthy and stable anatomical structures of bone and teeth must be preserved, as well as any scarring that does not interfere with the insertion and removal of the prosthesis [10].

Reconstructing the maxillectomy with an obturator has several advantages. In addition to replacing missing teeth, soft and hard tissues, it allows the restoration of the chewing, swallowing and phonation functions approximately in a normal manner, and forms a barrier between the nasal and oral cavities. Due to its removability, the obturator can be removed from the patient's mouth, allowing for easy inspection and early detection of any recurrent tumors [9].

The success of a prosthetic therapy is influenced by the biomechanical phenomena of support, stability and retention and depends on the knowledge and respect of anatomical elements and functional mechanisms [10].

Support is the resistance to movement of a prosthesis towards the tissue. The support available from the residual maxilla and from within the defect must be considered. The height and contour of the residual alveolar ridge is important for support in the edentulous patient. The large, broad ridge or the ridge with a square or ovoid tendency usually provide better support than the small, narrow ridge with a tapering contour. The broad, Flat palate is more conducive to support than the high tapering palate. In the acquired maxillary defects, The bony structures of the pterygoid plate and the anterior surface of the temporal bone are considered for positive support [11].

Retention : that quality inherent in the dental prosthesis acting to resist the forces of dislodgment along the path of placement [12]. Ridge size and shape infuence retention to a limited extent. The palatal contour infuences the ability to increase or decrease the interfacial surface tension. The broad, flat palate is more retentive than the high tapering palate. The square arch form is more conducive to retention than the tapering or ovoid arch form.

there will be more or less significant undercuts along the palatal resection line which play an important role in the retention of the obturator prosthesis [11].

Stability: the quality of a complete or removable partial denture to be firm, steady, or constant, to resist displacement by functional horizontal or rotational stresses [12]. Movement of the prosthesis within the horizontal plane can be anteroposterior, mediolateral, rotational, or a combination of any or all of these directions. As with retention and support specific areas of the residual maxilla, as well as the defect itself, must be considered in minimizing the extent of these potential movements.

Maximal extension of the prosthesis in all lateral directions must be provided. Occlusal stability in the centric and eccentric positions of the jaw is imperative to minimize the movement of the prostheses [11].

For the presented case, the objective was to aesthetically and functionally rehabilitate the patient by exploiting the elements favorable to retention, sustentation and stabilization.

The defect was not extensive so there was no need for making hollow bulb obturator and the prosthesis was made in conventional manner.

Post treatment photographs of the patient showed a marked improvement in aesthetics by replacement of missing teeth and restoration of the previously depressed nasomaxillary region. 


\section{CONCLUSION}

The goals of rehabilitating acquiered maxillary defects are separation of oral and nasal cavities to allow adequate mastication, deglutination, articulation the soft tissue support to restore acceptable esthetic to improve the quality of life of these individuals.

\section{Conflict of interest :}

The Author(s) declare(s) that there is no conflict of interest he publication of this paper.

\section{BIBLIOGRAPHY}

1. Vigarios E. Destruhaut F. Pomar P.Problématique psychosociale en cancérologie cervico-faciale : point de vue de l'odontostomatologiste-EMC. Elsevier Masson SAS, Paris. Médecine buccale, 28-870-M-10. 2010.

2. Payement G, Cariou JL, Cantaloube D, Bellaviour A. Pertes de substance des maxillaires. Encycl Med Chir Elsiever, Paris), Odontologie/Stomatologie 1995;22-087-E-10:1-20.

3. Chelly H, Kadiri F, Laalou Y, Chekkoury L, Benchekroun Y. La réhabilitation prothétique : une nécessité dans les cancers du maxillaire supérieur. Revue Marocaine Odontologie 1998;26:15-16.

4. omar P, Dichamp J. Introduction à la prothèse maxillo-faciale.Encycl Med Chir (Elsiever, Paris), Odontologie 2004;22066-B-50:1-7.

5. Curtis DA, Plesh O, Miller AJ, Curtis TA, Sharma A, Schweitzer R, Hilsinger RL, Shour L, Singer M: A comparision of masticatory function in patients without reconstruction of the madible. Head Neck 1997, 19, $287-296$

6. Cardelli , E. Bigelli , V. Vertucci , F. Balestra, M. Montani , S. De Carli , C. Arcuri. Palatal Obturators in patients after maxillectomy- A case report : Oral \&Implantology 2014 Jul-Sep; 7(3): 86-92.

7. ]. BENTAHAR O., POMAR P., FUSARO S., BENFDIL F., AGUENAOU A., ABDEDINE A. Prothèses obturatri- ces après maxillectomie: bases fondamentales et thérapeutiques. Encycl. Med. Chir., Stomatol. Paris: Elsevier Masson SAS, 2008; 22-066-B-58. $\mu$

8. El Assraoui, K., Ouaalla, M., Hatim, A. Cheikh, Y., Bellemkhannate, S. ESTHETIC SUCCESS IN COMPLETE DENTURE, International Journal of Information Research and Review Vol. 06, Issue, 06, pp.6351-6354, June, 2019

9. M.N. Alhajj et al. Maxillary obturator prosthesis for a hemimaxillectomy patient, The Saudi Journal for Dental Research (2016) 7, 153-159

10. DIENG L. et al. REHABILITATIONPROTHETIQUE PAR UNOBTURATEUR RIGIDE D'UNE VASCULARITE DE WEGENER A localisation MAXILLAIRE: RAPPORT DE CAS. Rev. Col. Odonto-Stomatol. Afr. Chir. Maxillo-fac., 2013 vol.20, n²1, pp. 59-64

11. KEYF F. , Obturator prostheses for hemimaxillectomy patients Journal, of Oral Rehabilitation 2001 28; 821-829

12. Keith J. Ferro et al, THE GLOSSARY OF PROSTHODONTIC TERMS, THE JOURNAL OF PROSTHETIC DENTISTRY, May 2017, Volume 117 Issue 5S 